\title{
Comparative Design and Cost Analysis of Cylindrical Storage Tanks with Different Head Types by Using COMPRESS
}

\author{
M. Tahir Altinbalik ${ }^{1}$, Selin İsencik ${ }^{2}$ \\ ${ }^{1}$ Trakya University Faculty of Engineering, Edirne/TURKEY \\ ${ }^{2} \mathrm{KM}$ Heavy Industries, Tekirdağ/TURKEY \\ tahira@trakya.edu.tr; s.isencik@gmail.com
}

\begin{abstract}
Storages or transmission tanks as a pressure vessel appear in various areas as diving cylinder, reactor technology, petrochemical industry, distillation towers and rainwater harvesting tank. The main goal of this study is to propose a simple method to solve, with minimum effort and acceptable reasonable accuracy, the problem of designing a storage vessel subjected to uniform internal pressure by using a commercial program. Besides it discusses the use of stainless steel instead of carbon steel which is preferred in general in the construction of tanks. For this purpose a storage tank has been designed for $10 \mathrm{~atm}$ of internal pressure and a temperature of $120{ }^{\circ} \mathrm{C}$ and capacity of 1500 lt. The use of two different materials and three different head types has been chosen for the tank. The COMPRESS program, which is preferred for obtaining quick results in the design of this type of tank, has been briefly introduced, and the design makes use of this program and also meets the ASME Boiler \& Pressure Vessel Code, Section VII, Rules for Construction of Pressure Vessels Division 1 standards. Finally, weight, ease of production and cost analyses of the tank design has been made with respect to the different types of material and head type used.
\end{abstract}

Keywords: Storage tanks, Pressure vessel, COMPRESS, ASME, Cost analysis

\section{Introduction}

Pressure vessels and storage tanks are used to store and transmit liquids, vapours and gases under pressure. In recent years they are widely used in space vehicles, aircrafts, nuclear power plants and many other engineering applications such as recompression chamber, reactor technology, the chemical industry, distillation towers and hyperbaric oxygen therapy chamber. These tanks commonly have the form of cylinders, spheres, cones, ellipsoids, tori, or composites of these. A common design is a cylinder with end caps called heads. The heads are typically hemispherical, ellipsoidal or torispherical [1]. Many tanks are made of steel but glass-reinforced plastic, thermoplastic and polyethylene tanks are increasing in popularity. As known, in order to obtain adequately mechanical strength in applications where carbon steel would suffer corrosion, special corrosion resistant material should also be used. During the last three decades considerable research effort has been made in the applications of some techniques to analyse pressure vessel and storage tank design problems.

As reported by Altınbalık and Kabak[2], a pioneering work on optimization techniques for designing pressure vessels has been presented by Middletown and Owen, who used parametric optimization techniques to minimize the maximum shear stress in the design of a pressure vessel torispheric end modelled with axisymmetric finite elements. Altınbalık also discussed the use of stainless steel instead of pressure vessel steel P275 GH by means of cost and weight analysis. In the mentioned study the required sheet thickness calculated by the empirical formulas according to AD 2000 pressured vessels standard and then results examined by the SolidWorks analysis module. The finite element method was applied to determine the state of stress in the cylindrical shell by Petrovic [3]. Al-Gahtani et al [4] presented the findings of a finite element study of the effect of cap size on the stresses near the junction of a cylindrical nozzle with a spherical vessel under internal pressure. Guidelines for choosing appropriate shape and size for the vessels that minimize material and manufacturing cost for cylindrical vessels was performed by Proczka et al [5]. Eipakchi [6] calculated the stresses and displacements of a pressure vessel with varying thickness under non-uniform internal pressure using higher-order shear deformation theory. Chen and Rotter [7] obtained the stresses of stiffening ring on tank using a linear shell bending theory. Gong et al [8] performed a finite element analysis of open top tanks and explained that the structure parameters of top stiffening rings play a significant role on the failure of the tank. Ghisi [9] studied the parameters affecting the sizing of rainwater tanks for domestic use and recommended that regional assessment of rainwater tank sizing be carried out by taking into account local rainfall data, roof areas, number of 
residents, potable water demand, and rainwater demand. Tam et al [10] compared the cost of procurement, installation and operation of rainwater tanks to the benefits of the use of a rainwater tank in an empirical study to aid residential decisionmaking. Santos and Pinto [11] concluded that variation in rainfall profile has the most significant effect on the optimal tank size when they applied different criteria in the sizing of rainwater storage tanks. Okoye et al [12] proposed an optimization model to determine the optimal tank size of a single residential housing unit for rainwater harvesting and storage.

In the present study a storage tank has been designed for $10 \mathrm{~atm}$ of internal pressure and a temperature of $120^{\circ} \mathrm{C}$ and capacity of $1500 \mathrm{lt}$. The use of two different materials and three different head types has been chosen for the tank. The COMPRESS program, which is preferred for obtaining quick results in the design of this type of tank, has been briefly introduced, and the design makes use of this program. Finally, weight, ease of production and cost analyses of the tank design has been made with respect to the different types of material and head type used.

\section{Theoretical Analysis and COMPRESS}

In design by calculations, two methodologies are usually described in storage tanks named; design by formulae and design by analysis. The first one defines relations for standard geometries: when it is used with the design stress, it leads to the minimum thickness of the vessel or component [9]. The thickness of the cylinder is only one part of the design. Other factors which affect the design are the length of the cylinder and size. Design by analysis is performed by the commercial programs.

COMPRESS is an engineering productivity tool that models, calculates and creates reports for ASME pressure vessels and heat exchangers. COMPRESS 3D solid models integrate with leading drafting and plant design systems. It is a very powerful and user-friendly program and eliminates the time-consuming, manual iteration required by other software to design entire vessels or individual components. While designing new vessels and exchangers or rating existing equipment COMPRESS can be used easily. For new designs, COMPRESS selects sizes, thicknesses and ratings to meet Code requirements. Firstly, sheet thickness values of the main body and the head is calculated by empirical formulas according to given in ASME sec VIII Div I. Then these results are compared the results with obtained from COMPRESS programme. Finally the results are controlled by the Authorized Inspector (AI) and accepted. For rating mode COMPRESS calculates the MAP (Maximum Allowable Pressure) and MAWP (Maximum Allowable Working Pressure) and minimum thickness for existing geometry. The COMPRESS main screen has several components and shown in Fig.1.a.

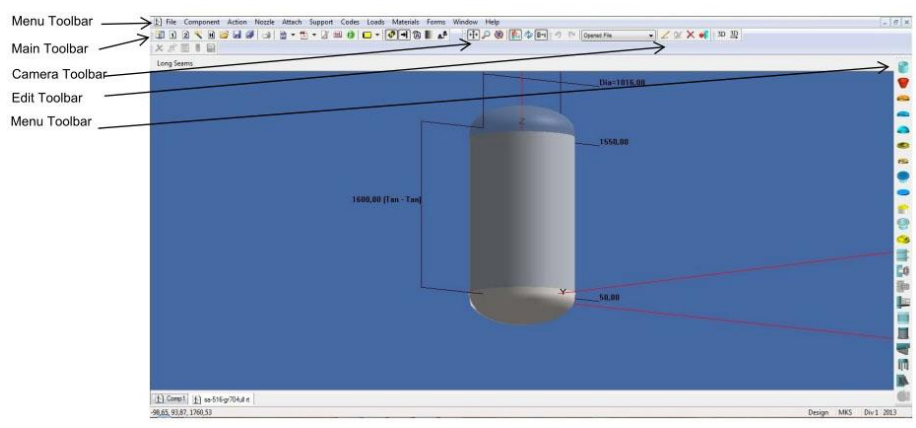

(a)

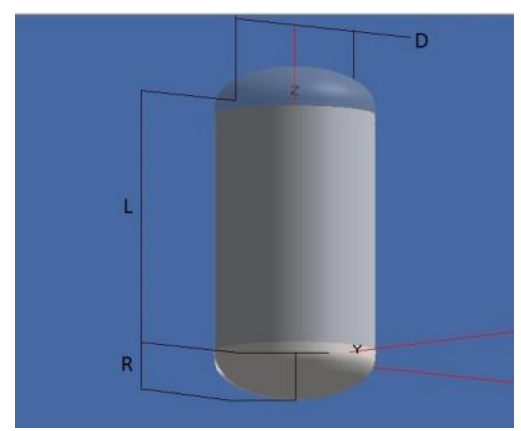

(b)

Fig. 1: Sample screenshot of COMPRESS. a) Main screen of COMPRESS and components b) Schematic view of the tank and related sizes.

As stated previously the use of two different materials and three different head types has been chosen for the tank which has $10 \mathrm{~atm}$. internal pressure and $1000 \mathrm{~mm}$. outer diameter. Head types has been chosen ellipsoidal, torispherical and hemispherical. Storage tanks are often cylindrical in shape and perpendicular to the ground. Schematic representation of the tank and related dimensions are given in Fig.1.b and Table 1.

\subsection{Related Equations}

In a cylindrical shell the minimum required thickness of shell is given as; 


$$
t=\frac{P R}{S E-0.6 P}
$$

On the other hand the minimum required thickness at the thinnest point after forming of ellipsoidal, torispherical and hemispherical heads under pressure is calculated by appropriate formulas given in literature. For ellipsoidal heads the thickness is calculated as;

$$
t=\frac{P D}{2 S E-0.2 P}
$$

For hemispherical heads the thickness is calculated as;

$$
t=\frac{P R}{2 S E-0.2 P}
$$

and for torispherical heads the thickness is calculated as;

$$
t=\frac{P L M}{2 S E-0.2 P}
$$

where:

$\mathrm{P}=$ Internal design pressure

$\mathrm{R}=$ Inside radius of the shell course under consideration

$\mathrm{D}=$ Inside diameter of the head

$\mathrm{S}=$ Maximum allowable stress value

$\mathrm{E}=$ Joint efficiency (When the tank design is required full radiographed it is equal to 1.00)

$\mathrm{L}=$ Inside spherical or crown radius for torispherical heads

$\mathrm{M}=\mathrm{A}$ factor in the equations for torispherical heads depending on the head proportion $\mathrm{L} / \mathrm{r}$

In ASME BPVC standards the minimum required thickness of shells under internal pressure should not be less than that calculated by the formulas.

Table 1: Geometrical dimensions of the tank for different head types.

\begin{tabular}{|l|c|c|c|}
\hline Dimensions & $\begin{array}{c}\mathrm{L}_{\text {tank }} \\
(\mathrm{mm})\end{array}$ & $\begin{array}{c}\mathrm{D} \\
(\mathrm{mm})\end{array}$ & $\begin{array}{c}\mathrm{R} \\
(\mathrm{mm})\end{array}$ \\
\hline Ellipsoidal & 1600 & 1000 & 256,5 \\
\hline Torispherical & 1600 & 1000 & 263,8 \\
\hline Hemispherical & 1250 & 1003 & 504,5 \\
\hline
\end{tabular}

\subsection{Material Selection and Design}

Firstly, SA-516 GR70 was chosen in order to manufacturing the vessel. SA-516 GR70 is one of the most popular steel grades. It offers greater tensile and yield strength when compared the others. It is primarily intended for use in welded pressure vessels and has excellent notch toughness and is used in both pressure vessels and industrial boilers. Austenitic stainless steel was chosen in order to compare with the SA-516 GR70 for several parameters. Austenitic (18-8) stainless steel alloys are strong, light, ductile and readily available in a variety of forms. They resist corrosion and oxidation. They have also exhibited good strength and toughness. There are many grades of austenitic stainless steels, the most popular of which are 304 and 304L. In the presented study SA 240-304L was chosen as a compare material with the SA-516 Gr70. The chemical composition and flow stress of both steels are given in Table 2. After choosing the materials design parameters was determined and these parameters was entered the COMPRESS program screen. Maximum allowable stress values of the 
chosen materials for $120^{\circ} \mathrm{C}$ were read from ASME-BPVC $2013 \mathrm{Sec}$ II Part D. A sample program screen is also given in Fig.2.

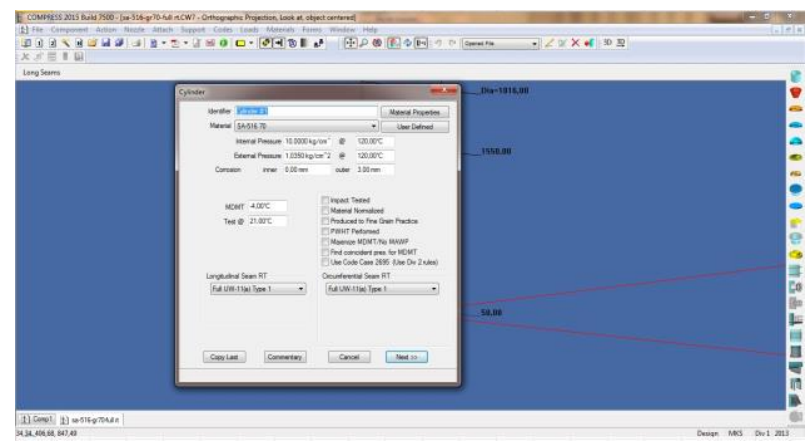

Fig. 2: A sample design screen of COMPRESS.

Table 2: The chemical composition and maximum allowable stress of both steels.

\begin{tabular}{|l|c|c|c|c|c|c|c|c|c|}
\hline Grade & $\mathrm{C}$ & $\mathrm{Si}$ & $\mathrm{Mn}$ & $\mathrm{P}$ & $\mathrm{S}$ & $\mathrm{Cr}$ & $\mathrm{Mo}$ & $\mathrm{Ni}$ & $\begin{array}{c}\mathrm{S} \\
(\mathrm{MPa})\end{array}$ \\
\hline SA-516 GR70 & $0.1-0.22$ & 0.6 & $1.0-1.7$ & 0.03 & 0.03 & 0.3 & 0.08 & 0.3 & 138 \\
\hline SA-240 304L & 0.03 & 0.75 & 2.0 & 0.045 & 0.03 & $18-20$ & - & $8-12$ & 115 \\
\hline
\end{tabular}

\section{Results and Discussion}

\subsection{Sheet Thicknesses}

Body sheet thickness calculation values for three different types of header are shown in Figure 3.a-3.c. The same sheet thickness has been calculated for all three head types as $6.57 \mathrm{~mm}$ because body plate thickness calculations are independent of the head type. The program requires the body plate thickness value to be chosen, and this value is entered as $8 \mathrm{~mm}$ in accordance with ASME BPVC standards and from experience. The program calculates MAP and MAWP values using this input and presents them to the user. Maximum allowable pressure (MAP) value is the maximum unit pressure permitted in a given material used in a vessel constructed under ASME Design rules. Maximum allowable working pressure (MAWP) for a vessel is the maximum internal or external pressure permissible at the top of the vessel in its normal operating position at the designated coincident temperature specified for that pressure.

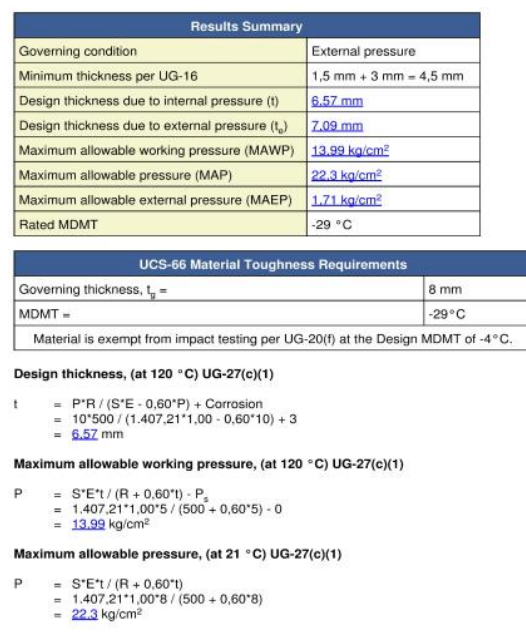

a)

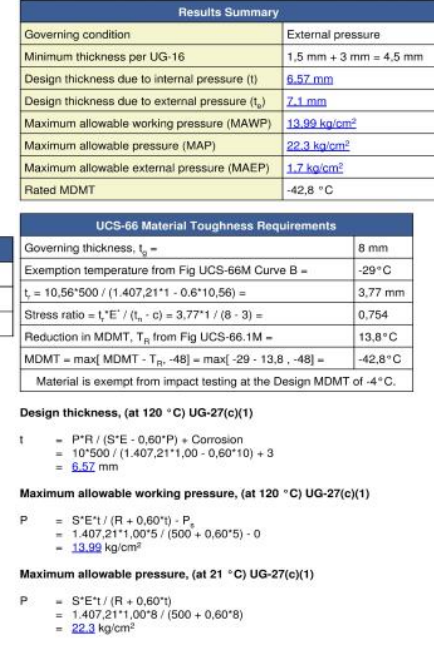

b)

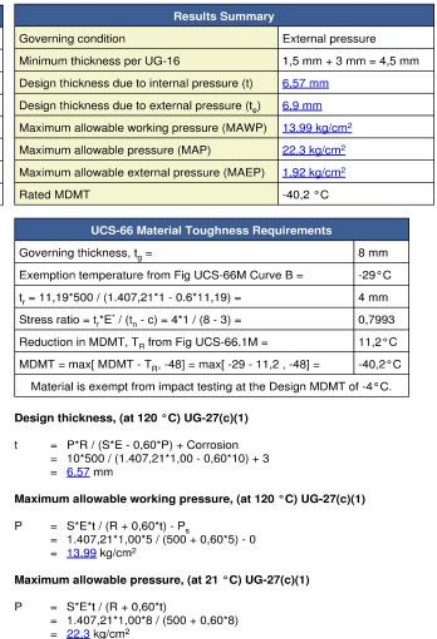

c)

Fig. 3: Thickness summary screen of main body for SA-516 GR70. a) Use of ellipsoidal head b) Use of torispherical head c) Use of hemispherical head. 
The next step is the calculation of the head sheet thickness, according to the head type. The sheet thicknesses relating to all three head types calculated by the program, and the sheet thicknesses that are entered by the user in the program in accordance with ASME BPVC standards are presented in Figure 4.a-4.c. At this point, it is necessary to evaluate ellipsoidal and torispherical heads in one category and hemispherical head in a different category. For ellipsoidal and torispherical heads, body and head sheet thicknesses are preferred to be as close as possible to each other. Consequently, the values used in the program take into consideration the body thickness values shown in the calculation screens of Figure 3.a-3.c. When entering these values, the manufacturing characteristics of the heads are also important. The design assumes that ellipsoidal and torispherical heads will thin down to between 8 and $8.5 \mathrm{~mm}$ from the initial sheet thickness of $10 \mathrm{~mm}$ during the drawing stage, and the chosen value is entered to the program. The situation is a little bit different for hemispherical heads. As known a hemispherical head has approximately half the thickness compared the others with the same pressure value. Therefore, it is convenient enough to choose the standard thickness closest to that calculated by the program. Thus, in the case of hemispherical heads, the manufacturing stage can be started with $8 \mathrm{~mm}$ of body thickness and $5 \mathrm{~mm}$ of head thickness.

\begin{tabular}{|l|l|}
\hline \multicolumn{2}{|c|}{ Results Summary } \\
\hline Governing condition & internal pressure \\
\hline Minimum thickness per UG-16 & $1,5 \mathrm{~mm}+3 \mathrm{~mm}=4,5 \mathrm{~mm}$ \\
\hline Design thickness due to internal pressure $(\mathrm{t})$ & $\underline{6.56 \mathrm{~mm}}$ \\
\hline Design thickness due to external pressure $\left(\mathrm{t}_{\mathrm{e}}\right)$ & $\underline{5.58 \mathrm{~mm}}$ \\
\hline Maximum allowable working pressure (MAWP) & $\underline{14.06 \mathrm{~kg} / \mathrm{cm}^{2}}$ \\
\hline Maximum allowable pressure (MAP) & $\underline{2.48} \mathrm{~kg} / \mathrm{cm}^{2}$ \\
\hline Maximum allowable external pressure (MAEP) & $\underline{3.91 \mathrm{~kg} / \mathrm{cm}^{2}}$ \\
\hline Straight Flange governs MDMT & $-45^{\circ} \mathrm{C}$ \\
\hline
\end{tabular}

Design thickness for internal pressure, (Corroded at $\left.120^{\circ} \mathrm{C}\right)$ UG-32(d)(1)

$t=P^{*} \mathrm{D} /\left(2^{*} \mathrm{~S}^{*} \mathrm{E}-0,2^{*} \mathrm{P}\right)+$ Corrosion

$=10^{*} 1.000 /\left(2^{*} 1.407,21^{*} 1-0,2^{*} 10\right)+3$

$=6.56 \mathrm{~mm}$

Maximum allowable working pressure, (Corroded at $\left.120^{\circ} \mathrm{C}\right)$ UG-32(d) $(1)$

$P=2^{*} S^{*} E^{*} t /\left(D+0,2^{*} t\right)-P_{s}$

$=2^{*} 1.407,21^{*} 1^{*} 5 /\left(1.000+0,2^{*} 5\right)-0$

$14,06 \mathrm{~kg} / \mathrm{cm}^{2}$

Maximum allowable pressure, (New at $\left.21^{\circ} \mathrm{C}\right)$ UG-32(d)(1)

$P=2^{*} S^{*} E^{*} t /\left(D+0,2^{*} t\right)-P_{s}$

$=2 * 1.407,21^{*} 1^{*} 8 /\left(1.000+0,2^{*} 8\right)-0$

$=2248 \mathrm{~kg} / \mathrm{cm}^{2}$

Design thickness for external pressure, (Corroded at $\left.120^{\circ} \mathrm{C}\right)$ UG-33(d)

a)

\begin{tabular}{|c|c|c|c|}
\hline \multicolumn{4}{|c|}{ Results Summary } \\
\hline \multicolumn{3}{|c|}{ Governing condition } & internal pressure \\
\hline \multicolumn{3}{|c|}{ Minimum thickness per UG-16 } & $1,5 \mathrm{~mm}+3 \mathrm{~mm}=4,5 \mathrm{~mm}$ \\
\hline \multicolumn{3}{|c|}{ Design thickness due to internal pressure ( $\mathrm{t}$ ) } & $7.73 \mathrm{~mm}$ \\
\hline \multicolumn{3}{|c|}{ Design thickness due to external pressure $\left(t_{\mathrm{e}}\right)$} & $5.92 \mathrm{~mm}$ \\
\hline \multicolumn{3}{|c|}{ Maximum allowable working pressure (MAWP) } & $10.56 \mathrm{~kg}_{\mathrm{f}} \mathrm{cm}^{2}$ \\
\hline \multicolumn{3}{|c|}{ Maximum allowable pressure (MAP) } & $16.89 \mathrm{~kg}_{\mathrm{f}} \mathrm{cm}^{2}$ \\
\hline \multicolumn{3}{|c|}{ Maximum allowable external pressure (MAEP) } & $3.05 \mathrm{~kg} / \mathrm{cm}^{2}$ \\
\hline \multicolumn{3}{|c|}{ Straight Flange governs MDMT } & $-48^{\circ} \mathrm{C}$ \\
\hline \multicolumn{4}{|c|}{ Note: Endnote 90 used to determine allowable stress. } \\
\hline \multicolumn{4}{|c|}{ Factor M } \\
\hline \multicolumn{3}{|c|}{$M=1 / 4^{*}\left[3+(L / r)^{1 / 2}\right]$} & \\
\hline Corroded & $M=1 / 4^{*}\left[3+(1.014 / 200)^{1 / 2}\right]$ & 1,312 & \\
\hline New & $M=1 / 4^{*}\left[3+(1.014 / 200)^{1 / 2}\right]$ & 1,312 & \\
\hline
\end{tabular}

Design thickness for internal pressure, (Corroded at $120^{\circ} \mathrm{C}$ ) Appendix 1-4(d) t

$t=P^{*} L^{*} M /\left(2^{*} S^{*} E-0,2^{*} P\right)+$ Corrosion $=10^{*} 1.014^{*} 1,3129 /\left(2^{*} 1.407,21^{*} 1-0,2^{*} 10\right)+3$ $=7.73 \mathrm{~mm}$

Maximum allowable working pressure, (Corroded at $120^{\circ} \mathrm{C}$ ) Appendix 1-4(d) $P$

$P=2^{*} S^{*} E^{*} t /\left(L^{*} M+0,2^{*} t\right) \cdot P_{s}$

/ $\left(1.014^{*} 1,3129+0,2 * 5\right)-0$ $=10.56 \mathrm{~kg} / \mathrm{cm}^{2}$

Maximum allowable pressure, (New at $21^{\circ} \mathrm{C}$ ) Appendix 1-4(d)

$P=2^{*} S^{*} E^{*} t /\left(L^{*} M+0,2^{*} t\right)-P$

$=2^{*} 1.407,21^{*} 1^{*} 8 /\left(1.014^{*} 1,3129+0,2^{*} 8\right)-0$
$=16.89 \mathrm{ka} / \mathrm{cm}^{2}$

b)

\begin{tabular}{|l|l|}
\hline \multicolumn{3}{|c|}{ Results Summary } \\
\hline Governing condition & Internal pressure \\
\hline Minimum thickness per UG-16 & $1,5 \mathrm{~mm}+3 \mathrm{~mm}=4,5 \mathrm{~mm}$ \\
\hline Design thickness due to internal pressure $(\mathrm{t})$ & $\underline{4.79 \mathrm{~mm}}$ \\
\hline Design thickness due to external pressure $\left(\mathrm{t}_{\mathrm{e}}\right.$ ) & $\underline{4.45 \mathrm{~mm}}$ \\
\hline Maximum allowable working pressure (MAWP) & $11.19 \mathrm{~kg}_{\mathrm{cm}}{ }^{2}$ \\
\hline Maximum allowable pressure (MAP) & $\underline{27.95 \mathrm{~kg}^{\mathrm{cm}}{ }^{2}}$ \\
\hline Maximum allowable external pressure (MAEP) & $1.97 \mathrm{~kg} / \mathrm{cm}^{2}$ \\
\hline Rated MDMT & $-29^{\circ} \mathrm{C}$ \\
\hline
\end{tabular}

CS-66 Material Toughness Requirements

\begin{tabular}{|l|l|}
\hline Governing thickness, $\mathrm{t}_{\mathrm{g}}=$ & $5 \mathrm{~mm}$ \\
\hline MDMT $=$ & $-29^{\circ} \mathrm{C}$ \\
\hline \multicolumn{2}{|c|}{ Material is exempt from impact testing per UG-20(f) at the Design MDMT of $-4^{\circ} \mathrm{C}}$. \\
\hline
\end{tabular}

Design thickness, (at $120^{\circ} \mathrm{C}$ ) UG-32(f)

$=P^{*} R /\left(2^{*} S^{*} E \cdot 0,20^{*} P\right)+$ Corrosion $=10^{*} 502,5 /\left(2^{*} 1.407,21^{*} 1,00-0,20^{*} 10\right)+3$ $=\underline{4.79} \mathrm{~mm}$

Maximum allowable working pressure, (at $120^{\circ} \mathrm{C}$ ) UG-32(f)

$=2^{*} S^{*} E^{*} t /\left(R+0,20^{*} t\right)-P_{s}$

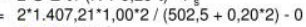
$=2 \cdot 1.407,21 * 1.00$
$=11.19 \mathrm{~kg} / \mathrm{cm}^{2}$

Maximum allowable pressure, (at $\left.21^{\circ} \mathrm{C}\right)$ UG-32(f)

$P \quad=2^{*} S^{*} E^{*} t /\left(R+0,20^{*} t\right)$

$=2 * 1.407,21 * 1,00^{*} 5 /(502,5+0,20 * 5)$

$=\underline{27.95} \mathrm{~kg} / \mathrm{cm}^{2}$

c)

Fig. 4: Thickness summary screen of heads for SA-516 GR70

a) Use of ellipsoidal head b) Use of torispherical head c) Use of hemispherical head.

Sheet thickness values calculated by the program for the use of stainless steel material are shown in Figure 5.a-5.c. As seen in these figures, the sheet thickness value for the main body was calculated to be $4.29 \mathrm{~mm}$. The value entered by the user, which is suitable according to the standards, is $6 \mathrm{~mm}$, and MAP and MAWP calculations are made by the program using this value. Hemispherical head is also considered in the different category when choosing the head sheet thickness. As sheet thickness values calculated for ellipsoidal and torispherical head use are different from each other, the design uses a value of $6.5 \mathrm{~mm}$ to calculate MAP and MAWP values, as seen in Fig.6.a-6.c. According to experience, heads will be drawn when using $8 \mathrm{~mm}$ sheet and a head thickness of $6.5 \mathrm{~mm}$ will be obtained at the end of the process. In the case of hemispherical head use, and the reasons described above, a standard sheet thickness that is the closest value to the calculation of the program has been chosen and the MAP/MAWP calculations have been made accordingly. 


\begin{tabular}{|c|c|}
\hline \multicolumn{2}{|l|}{ Results Summary } \\
\hline Governing condition & Internal pressure \\
\hline Minimum thickness per UG-16 & $1,5 \mathrm{~mm}+0 \mathrm{~mm}=1,5 \mathrm{~mm}$ \\
\hline Design thickness due to internal pressure (t) & $4.29 \mathrm{~mm}$ \\
\hline Design thickness due to external pressure $\left(l_{\ell}\right)$ & $4.17 \mathrm{~mm}$ \\
\hline Maximum allowable working pressure (MAWP) & $13.97 \mathrm{~kg} \mathrm{~cm}^{2}$ \\
\hline Maximum allowable pressure (MAP) & $13.97 \mathrm{~kg}_{\mathrm{cm}}^{2}$ \\
\hline Maximum allowable external pressure (MAEP) & $2.63 \mathrm{~kg} / \mathrm{cm}^{2}$ \\
\hline Rated MDMT & $-196^{\circ} \mathrm{C}$ \\
\hline \multicolumn{2}{|c|}{ UHA-51 Materlal Toughness Requirements } \\
\hline \multicolumn{2}{|c|}{ Rated MDMT per UHA-51(d)(1)(a), (carbon content does not exceed $0,10 \%)=-196^{\circ} \mathrm{C}$} \\
\hline \multicolumn{2}{|c|}{ Material is exempt trom impact testing at the Design MDMT of $-4^{\circ} \mathrm{C}$. } \\
\hline \multicolumn{2}{|l|}{ Design thickness, (at $120^{\circ} \mathrm{C}$ ) UG-27(c)(1) } \\
\hline \multicolumn{2}{|l|}{$\begin{aligned} & =P * R /\left(S^{*} \cdot E \cdot 0,0,60^{*} P\right)+\text { Corrosion } \\
& =10^{*} 500 /\left(1.172,67^{*} 1,00 \cdot 0,60^{*} 10\right)+0 \\
& =4.29 \mathrm{~mm}\end{aligned}$} \\
\hline \multicolumn{2}{|c|}{ Maximum allowable working pressure, (at $120^{\circ} \mathrm{C}$ ) UG-27(c)(1) } \\
\hline \multicolumn{2}{|c|}{$\begin{aligned} P & =S^{*} E^{*} t /\left(R+0,60^{*} t\right)-P_{s} \\
& =1.172,67^{*}, 1,00^{*} 6 /\left(500^{\circ}+0,60^{*} 6\right)-0 \\
& =13.97 \mathrm{~kg}^{2} \mathrm{~cm}^{2}\end{aligned}$} \\
\hline \multicolumn{2}{|c|}{ Maximum allowable pressure, (at $21^{\circ} \mathrm{C}$ ) UG-27(c)(1) } \\
\hline $\begin{aligned} P & =S^{*} E^{*} t /\left(R+0,60^{*} t\right) \\
& =1.172,67^{*} 1,00^{*} 6 /\left(500+0,60^{*} 6\right) \\
& =13.97 \mathrm{~kg}^{\prime} \mathrm{cm}^{2}\end{aligned}$ & \\
\hline
\end{tabular}

a)

\begin{tabular}{|c|c|}
\hline \multicolumn{2}{|l|}{ Results Summary } \\
\hline Governing condition & Internal pressure \\
\hline Minimum thickness per UG-16 & $1,5 \mathrm{~mm}+0 \mathrm{~mm}=1,5 \mathrm{~mm}$ \\
\hline Design thickness due to internal pressure (t) & $4.29 \mathrm{~mm}$ \\
\hline Design thickness due to external pressure $\left(\mathrm{t}_{\mathrm{e}}\right)$ & $4.17 \mathrm{~mm}$ \\
\hline Maximum allowable working pressure (MAWP) & $13.97{\mathrm{~kg} / \mathrm{cm}^{2}}^{2}$ \\
\hline Maximum allowable pressure (MAP) & $13.97{\mathrm{~kg} / \mathrm{cm}^{2}}^{2}$ \\
\hline Maximum allowable external pressure (MAEP) & $2.62 \mathrm{~kg} / \mathrm{cm}^{2}$ \\
\hline Rated MDMT & $-196^{\circ} \mathrm{C}$ \\
\hline \multicolumn{2}{|c|}{ UHA-51 Material Toughness Requirements } \\
\hline \multicolumn{2}{|c|}{ Rated MDMT per UHA-51(d)(1)(a), (carbon content does not exceed $0,10 \%)=-196^{\circ}$} \\
\hline \multicolumn{2}{|c|}{ Material is exempt from impact testing at the Design MDMT of $-4^{\circ} \mathrm{C}$} \\
\hline \multicolumn{2}{|l|}{ Design thickness, (at $\left.120^{\circ} \mathrm{C}\right)$ UG-27(c)(1) } \\
\hline \multicolumn{2}{|c|}{$\begin{aligned} & =P * R /\left(S^{*} E-0,60^{*} P\right)+\text { Corrosion } \\
& =10^{*} 500 /\left(1.172,67^{* 1}, 00-0,60^{*} 10\right)+0 \\
& =4.29 \mathrm{~mm}\end{aligned}$} \\
\hline \multicolumn{2}{|c|}{ Maximum allowable working pressure, (at $\left.120^{\circ} \mathrm{C}\right)$ UG-27(c)(1) } \\
\hline \multicolumn{2}{|c|}{$\begin{aligned} P & =S^{*} E^{*} t /\left(R+0,60^{*} t\right)-P_{s} \\
& =1.172,67^{*}+1,00^{*} 6 /\left(500^{\circ}+0,60^{*} 6\right)-0 \\
& =13,97 \mathrm{~kg}^{\circ} \mathrm{cm}^{2}\end{aligned}$} \\
\hline \multicolumn{2}{|c|}{ Maximum allowable pressure, (at $\left.21^{\circ} \mathrm{C}\right)$ UG-27(c)(1) } \\
\hline $\begin{aligned} P & =S^{*} E^{*}+/\left(R+0,600^{*}\right) \\
& =1.172,67^{*} 1,00^{*} 6 /\left(500+0,60^{*} 6\right) \\
& =13.97 \mathrm{~kg}^{\prime} \mathrm{cm}^{2}\end{aligned}$ & \\
\hline
\end{tabular}

b)

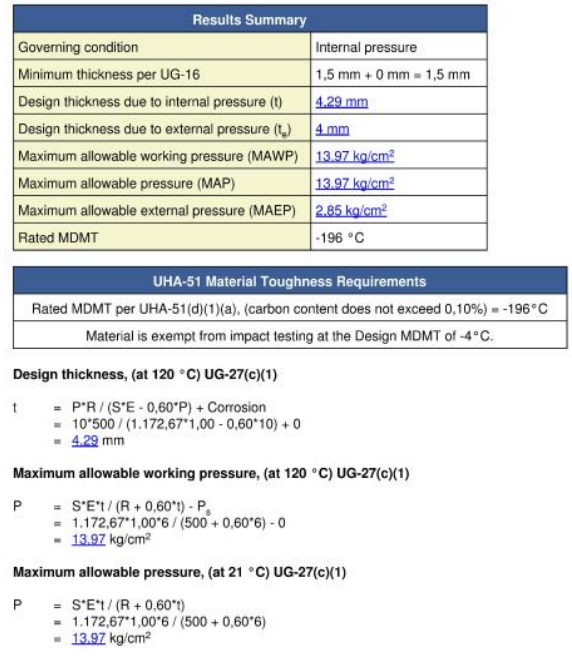

c)

Fig. 5: Thickness summary screen of main body for SA-240 304L

a) Use of ellipsoidal head b) Use of torispherical head c) Use of hemispherical head.

\begin{tabular}{|l|l|}
\hline \multicolumn{2}{|c|}{ Results Summary } \\
\hline Governing condition & internal pressure \\
\hline Minimum thickness per UG-16 & $1.5 \mathrm{~mm}+0 \mathrm{~mm}=1,5 \mathrm{~mm}$ \\
\hline Design thickness due to internal pressure $(\mathrm{t})$ & $4.27 \mathrm{~mm}$ \\
\hline Design thickness due to external pressure $\left(\mathrm{t}_{\mathrm{e}}\right)$ & $2.68 \mathrm{~mm}$ \\
\hline Maximum allowable working pressure (MAWP) & $15.23 \mathrm{~kg} / \mathrm{cm}^{2}$ \\
\hline Maximum allowable pressure (MAP) & $15.23 \mathrm{~kg} / \mathrm{cm}^{2}$ \\
\hline Maximum allowable external pressure (MAEP) & $3.46 \mathrm{~kg} / \mathrm{cm}^{2}$ \\
\hline Straight Flange governs MDMT & $-196^{\circ} \mathrm{C}$ \\
\hline
\end{tabular}

Design thickness for internal pressure, (Corroded at $\left.120{ }^{\circ} \mathrm{C}\right)$ UG-32(d)(1)

$t=P^{*} D /\left(2^{*} S^{*} E \cdot 0,2^{*} P\right)+$ Corrosion

$=10^{*} 1.000$
$=4.27 \mathrm{~mm}$

Maximum allowable working pressure, (Corroded at $\left.120^{\circ} \mathrm{C}\right)$ UG-32(d)(1)

$P=2^{*} S^{*} E^{*} t /\left(D+0,2^{*} t\right)-P$

$2^{*} 1.172,67^{*} 1^{*} 6,5 /\left(1.000+0,2^{*} 6,5\right)$.

Maximum allowable pressure, (New at $\left.21^{\circ} \mathrm{C}\right)$ UG-32(d)(1)

$P=2^{*} S^{*} E^{*} t /\left(D+0,2^{*} t\right)-P$ $=2^{*} 1.172,677^{*} 1^{*} 6,5 /\left(1.000+0,2^{*} 6,5\right)-0$
$=15.23 \mathrm{~kg} / \mathrm{cm}^{2}$

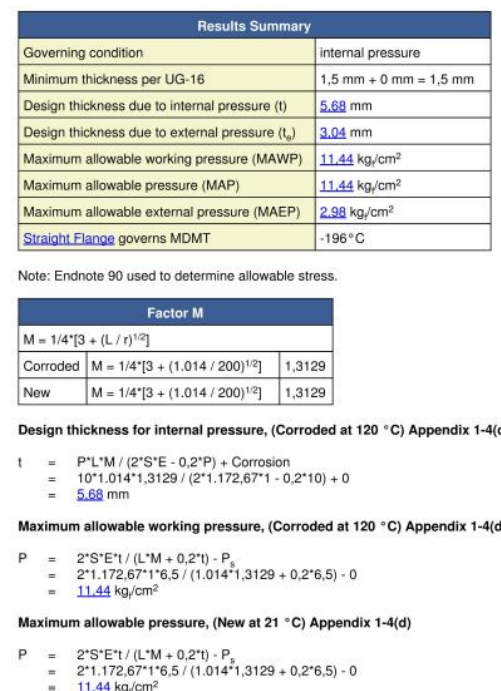

b)

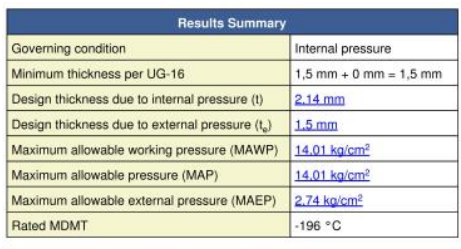

\begin{tabular}{l|l|l|l} 
Rated MOMT & $196^{\circ} \mathrm{C}$ \\
\hline
\end{tabular}

\section{Rated MDMT per UHA-51(d) (1)(a), (carion content does not exceed $0,10 \%)=-196^{\circ} \mathrm{C}$}

Material is exempt from impact testing at the Design MDMT of $-4^{\circ} \mathrm{C}$.

Design thickness, (at $120^{\circ} \mathrm{C}$ ) UG-32(f)

$=P^{*} \mathbf{P} /\left(2^{*} S^{*} E \cdot \cdot 0,20^{*} P\right)+$ Corrosion
$=10^{\circ} 501,5 /\left(2^{*} 1.172,67^{*} 1,00-0,20^{\circ} 10\right)+0$
$=2.14 \mathrm{~mm}$

Maximum allowable working pressure, (at $120^{\circ} \mathrm{C}$ ) UG-32(f)

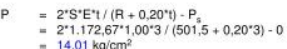

aximum allowable pressure, (at $21^{\circ} \mathrm{C}$ ) UG-32(f)

$P=2^{*} \cdot S^{*} E^{*}+/\left(R+0.20^{*}\right)$

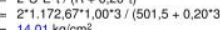

a)

c)

Fig. 6: Thickness summary screen of heads for SA-240 304L

a) Use of ellipsoidal head b) Use of torispherical head c) Use of hemispherical head.

\subsection{Weight and Cost Analysis}

In order to make a comparison in terms of cost analysis, the weight of the tanks, with respect to their material and head type, have been calculated with the help of the COMPRESS program. In Figure 7, the total weights of the storage tanks are presented for the three different head types by using SA-516 GR70 material. Since the design maintains a constant volume, the height of the tank is shorter for the same volume with the hemispherical head. Thus, the design using hemispherical head with SA-516 GR70 material is $7 \%$ lighter than with the ellipsoidal head, and $21 \%$ lighter than the one having a torispherical head. 


\begin{tabular}{|c|c|c|c|c|c|c|c|c|}
\hline \multicolumn{3}{|c|}{ Vessel Totals } & \multicolumn{3}{|c|}{ Vessel Totals } & \multicolumn{3}{|c|}{ Vessel Totals } \\
\hline & New & Corroded & & New & Corroded & & New & Corroded \\
\hline Operating Weight (kg) & 470 & 294 & Operating Weight (kg) & 552 & 377 & Operating Weight (kg) & 436 & 267 \\
\hline Empty Weight (kg) & 470 & 294 & Empty Weight (kg) & 552 & 377 & Empty Weight (kg) & 436 & 267 \\
\hline Test Weight (kg) & 1.987 & 1.811 & Test Weight (kg) & 2.094 & 1.918 & Test Weight (kg) & 1.948 & 1.779 \\
\hline Surface Area $\left(\mathrm{m}^{2}\right)$ & 7,61 & - & Surface Area $\left(\mathrm{m}^{2}\right)$ & 7,66 & - & Surface Area $\left(\mathrm{m}^{2}\right)$ & 7,24 & - \\
\hline Capacity $^{\star \star}$ (liters) & 1.518 & 1.518 & Capacity $^{\star \star}$ (liters) & 1.543 & 1.543 & Capacity $^{\star \star ~(l i t e r s) ~}$ & 1.513 & 1.513 \\
\hline \multicolumn{3}{|c|}{$\begin{array}{l}{ }^{\star \star} \text { The vessel capacity does not include } \\
\text { volume of nozzle, piping or other } \\
\text { attachments. }\end{array}$} & \multicolumn{3}{|c|}{$\begin{array}{l}\text { **The vessel capacity does not include } \\
\text { volume of nozzle, piping or other } \\
\text { attachments. }\end{array}$} & \multicolumn{3}{|c|}{$\begin{array}{l}{ }^{* *} \text { The vessel capacity does not include } \\
\text { volume of nozzle, piping or other } \\
\text { attachments. }\end{array}$} \\
\hline
\end{tabular}

a)

b)

c)

Fig. 7: Weight summary screen for SA-516 GR70

a) Use of ellipsoidal head b) Use of torispherical head c) Use of hemispherical head.

A similar table is presented in Figure 8 for SA-240 304L material. As shown in this table, the use of hemispherical head results in a material saving of approximately $27 \%$, when compared to ellipsoidal and torispherical heads.

\begin{tabular}{|l|c|c|}
\hline \multicolumn{3}{|c|}{ Vessel Totals } \\
\hline & New & Corroded \\
\hline Operating Weight $(\mathrm{kg})$ & 371 & 371 \\
\hline Empty Weight $(\mathrm{kg})$ & 371 & 371 \\
\hline Test Weight $(\mathrm{kg})$ & 1.888 & 1.888 \\
\hline Surface Area $\left(\mathrm{m}^{2}\right)$ & 7,57 & - \\
\hline Capacity** (liters) & 1.518 & 1.518 \\
\hline $\begin{array}{l}\text { **The vessel capacity does not include } \\
\text { volume of nozzle, piping or other } \\
\text { attachments. }\end{array}$ \\
\hline
\end{tabular}

a)

\begin{tabular}{|l|c|c|}
\hline \multicolumn{3}{|c|}{ Vessel Totals } \\
\hline & New & Corroded \\
\hline Operating Weight $(\mathrm{kg})$ & 369 & 369 \\
\hline Empty Weight $(\mathrm{kg})$ & 369 & 369 \\
\hline Test Weight $(\mathrm{kg})$ & 1.911 & 1.911 \\
\hline Surface Area $\left(\mathrm{m}^{2}\right)$ & 7,59 & - \\
\hline $\begin{array}{l}\text { Capacity } \\
\text { ** (liters) }\end{array}$ & 1.543 & 1.543 \\
\hline $\begin{array}{l}\text { **The vessel capacity does not include } \\
\text { volume of nozzle, piping or other } \\
\text { attachments. }\end{array}$ \\
\hline
\end{tabular}

b)

\begin{tabular}{|l|c|c|}
\hline \multicolumn{3}{|c|}{ Vessel Totals } \\
\hline & New & Corroded \\
\hline Operating Weight $(\mathrm{kg})$ & 267 & 267 \\
\hline Empty Weight $(\mathrm{kg})$ & 267 & 267 \\
\hline Test Weight $(\mathrm{kg})$ & 1.776 & 1.776 \\
\hline Surface Area (m²) & 7,17 & - \\
\hline Capacity** (liters) & 1.510 & 1.510 \\
\hline $\begin{array}{l}\text { ** The vessel capacity does not include } \\
\text { volume of nozzle, piping or other } \\
\text { attachments. }\end{array}$ \\
\hline
\end{tabular}

c)

Fig. 8: Weight summary screen for SA-240 304L

a) Use of ellipsoidal head b) Use of torispherical head c) Use of hemispherical head.

As the figures are examined together, the use of hemispherical head for SA-240 304L material results in the most reasonable design in terms of material weight. However, a comparison of both material and head manufacturing costs is used to make a detailed analysis that will guide us in choosing the appropriate design options. In Table 3, production costs of heads and unit $(\mathrm{kg})$ prices of materials are given.

Table 3: Compatarive Cost Analysis.

\begin{tabular}{|l|l|l|l|l|l|}
\hline Material & $\begin{array}{l}\text { Unit Price } \\
(\$ / \mathrm{kg})\end{array}$ & $\begin{array}{l}\text { Ellip. Head } \\
\text { Manuf. } \\
\text { Price }(\$)\end{array}$ & $\begin{array}{l}\text { Toris. Head } \\
\text { Manuf. } \\
\text { Price }(\$)\end{array}$ & $\begin{array}{l}\text { Hemisph. } \\
\text { Head Manuf. } \\
\text { Price }(\$)\end{array}$ & $\begin{array}{l}\text { Total Cost }(\$) \\
\text { Ellip/Toris/Sph }\end{array}$ \\
\hline $\begin{array}{l}\text { SA-516 } \\
\text { Gr70 }\end{array}$ & 0.9 & 110 & 45 & 800 & $530 / 545 / 1190$ \\
\hline $\begin{array}{l}\text { SA-240 } \\
\text { 304L }\end{array}$ & 2.85 & 100 & 40 & 700 & $1150 / 1100 / 1450$ \\
\hline
\end{tabular}


Using these values, the total cost for each design option is presented in the table. Cost of the rolling the main body is independent of the material; therefore, it has not been considered here. As seen in the table, costs don't differ widely. Numerous factors play a role in the production of a tank, aside from the design criteria that are present in the literature. Customer expectations, information obtained by experience and company production routines are some of these factors. Therefore, the aim of this study is to increase people's options, instead of presenting accurate information on a specific design. When evaluating Table 3 using this perspective, a tank with a hemispherical head using SA-516 GR70 material and a tank with an ellipsoidal or torispherical head using stainless steel have similar costs. However, stainless steel is much superior in terms of lifetime. When choosing SA-516 GR70 sheet, also known as carbon steel, it is suggested that the inner surface should be covered with vulcanized rubber (ebonite) with the addition of high amounts of sulfurs.

\section{Acknowledgements}

The authors especially wish to thank KM HEAVY INDUSTRIES and Mr. Oğuz HÜLAGÜ and Mr. Mehmet KÜÇÜKAVCU for permission of use of COMPRESS.

\section{References}

[1] D. Moss, Pressure Vessel Design Manual: Illustrated Procedures for Solving Major Pressure Vessel Design Problems. $3^{\text {rd }}$ Edition Gulf Professional Publishing, Elsevier, 2004.

[2] M. T. Altınbalık and T. Kabak, "Strength and cost analysis of stainless steel uses in the multiplace hyperbaric chambers," in Proceedings of the UNITECH2015 International Scientific Conference, Gabrovo, Bulgaria, 2015, vol. 3, pp. 137143.

[3] A. Petrovic, "Stress analysis in cylindrical pressure vessel with loads applied to the free end of a nozzle," Int. J. of Pressure Vessels\&Piping, vol. 78, pp. 485-493, 2001.

[4] H. Al-Gahtani, A. Khathlan, M. Sunar, and M. Naffa'a, "Local pressure testing of spherical vessels," Int. J. of Pressure Vessels\&Piping, vol. 114-115, pp. 61-68, 2014.

[5] J. J. Proczka, K. Muralidharan, D. Villela, J. H. Simmons, and G. Frantziskonis, "Guidelines for the pressure and efficient sizing of pressure vessels for compressed air energy storage," Energy Conversion and Management, vol. 65, pp. 597-605, 2013.

[6] H. R. Eipakchi, "Third-order shear deformation theory for stress analysis of a thick conical shell under pressure," J. of Mechanics of Materials and Structures, vol. 5, no. 1, pp. 1-17, 2010.

[7] J. F.Chen and J. M. Rotter, "Effective cross sections of asymmetric rings on cylindrical shells," J. Struct. Eng, vol. 124, no. 9, pp. 1074-1080, 1998.

[8] J. Gong, J. Tao, J .Zhao, S. Zeng, and T. Jin, "Effect of top stiffening rings of open top tanks on critical harmonic settlement," Thin Wall Struct., vol. 65, pp. 62-71, 2013.

[9] E. Ghisi, "Parameters influencing the sizing of rainwater tanks for use in houses," Water Resour. Manag. vol. 24, pp. 2381-2403, 2010.

[10] V. W. Y. Tam, L. Tam, and S. X. Zeng, "Cost effectiveness and trade off on the use of rainwater tank: an empirical study in Australian residential decision making," Resour. Conserv. Recycl. vol. 54, pp. 178-186, 2010.

[11] C. Santos and F. Taveira-Pinto, "Analysis of different criteria to size rainwater storage tanks using detailed methods," Resour. Conserv. Recycl., vol. 71, pp. 1-6, 2013.

[12] C. O. Okoye, O. Solyalı, and B. Akıntuğ, "Optimal sizing of storage tanks in domestic rainwater harvestingsystems: A linear programming approach,” Resour. Conserv. Recycl., vol. 104, pp. 131-140, 2015. 